\title{
Fig molasses: Processing Essentials and Organoleptic Properties
}

\section{Ossama Dimassi ${ }^{1 *}$, Fatimah Rizk ${ }^{1}$, Ehssan Sharif-Askari², Mohamed Rached², Raymond $\mathrm{Akiki}^{3}$}

\author{
${ }^{1}$ Department of Nutrition and Food Science, Lebanese International University, Beirut, Lebanon \\ ${ }^{2}$ Department of Biomedical Sciences, Lebanese International University, Beirut, Lebanon \\ ${ }^{3}$ Department of Business Administration, Lebanese International University, Beirut, Lebanon \\ *Corresponding authors: odimassi@gmail.com
}

\begin{abstract}
Local varieties of fig fruits (genus Ficus) are classified by their morphological characteristics mainly color of outer layer versus color inside. This has resulted in three categories, namely green outer layer with both white and red color inside and with outside and inside red color. Fig molasses produced following a traditional Lebanese recipe, using overripe-fresh-figs, was scrutinized to assess technical details such as fig molasses per fig conversion values (FMFCV) $(\mathrm{kg} / 100 \mathrm{~kg}$ figs) and organoleptic properties. Part of the prepared figs had $\mathrm{pH}$ adjusted to around 4.2 using citric acid. Concerning FMFCV there was no significant differences between molasses produced using the different fig cultivars. Water was added to the strained figs and a second extract was produced. FFMCV recognized from the first straining was significantly higher than that value recorded from the second straining. There was no significant difference between the two products concerning $\mathrm{pH}$, water activity and ash content. Fig molasses produced from $\mathrm{pH}$-adjusted figs had a significantly higher FFMCV, lower pH and higher ash content compared to those produced from non-pH-adjusted ones; however, no significant difference water activity was detected. Concerning organoleptic properties there was no significant difference between all the fig molasses produced. The use of the overripe figs shows how traditional methods have innate food waste reduction concept. Lower pH, higher FFMCV and no significant difference in the sensory attributes favor the use of the citric acid in the recipe since in would increase the production efficiency and would prolong the product shelf life.
\end{abstract}

Keywords-Fig; Fig molasses; Fig to fig molasses conversion value; Strained figs; $\mathrm{pH}$.

\section{INTRODUCTION}

Fig fruit, scientifically named "Ficus carica", is cultivated in most Mediterranean countries mainly in mild and dry areas (Polat \& Caliskan, 2008).

Many fruit trees such as fig, pinus, walnut, pomegranate, carob and pistachio are well adapted to the lebanese enviroment are not sufficiently exploited and are generaly neglected and found in marginal lands or peripheries of the orchards (Stover, Aradhya, Ferguson, \& Crisosto, 2007). Although they represent a great potential to the local and regional market (Migdadi et al., 2007).

Fig has long been consumed in the dried form. Therefore, most of the research has been directed towards dry fig culture ((Polat \& Özkaya, 2005).

In Lebanon as well as the Mediterian region and southern Arabia figs has always been an important part of the diet since they are an important spurce of carbohydrates, contain essential amino acids and are rich in vitamins B1, $\mathrm{B} 2$ and $\mathrm{C}$ and minerals (Flaishman, Rodov, \& Stover, 2008) (Vallejo, Marín, \& Tomás-Barberán, 2012).
Furthermore, the use of figs in cosmetics is well established (Aburjai \& Natsheh, 2003)

Fresh figs are highly perishable and prone for microbial spoilage even at cold temperatures. Figs falls in the category of climacteric fruits and to some extent sensitive to ethylene which stimulates softening and increase decay severity, if kept at temperatures equal to or higher than $5^{\circ} \mathrm{C}$ (Gözlekçi, Erkan, Karasahin Yildirim, \& Şahin, 2008).

The high perishability of the fruits makes the storage for long unachievable thus processing into dried fruits, jam or molasses is done (Flaishman et al., 2008) (Jawandha, Singh, Kaur, \& Arora, 2016). Molasses traditionally were also produced from many other ingredients such as carob and all were a way to have access to the nutritional benefits outside the production season and as natural sweeteners (Dimassi, Fawaz, \& Rached, 2019; Dimassi, Rached, Fawaz, \& Akiki, 2019). Moreover, fig molasses is a natural food that was produced traditionally (Gözlekçi 
et al., 2008). Molasses were used to conserve the very ripe figs which would be less fit for drying.

The aim is to study the characterize fig molasses to enable marketing and to standardize the production in order to increase the product efficiency. To assess the physicochemical properties, water activities, $\mathrm{pH}$ ash content for the 70 degrees brix molasses for both molasses produced with and without the addition of the citric acid (Kuchi, Gupta, \& Tamang, 2014) (Cevrimli, Kariptas, \& Ciftci, 2009) of the three cultivars are identified in this study. In addition, the most important indicator for the efficiency of production, namely the $\mathrm{Kg}$ figs to $\mathrm{Kg}$ fig molasses produced is calculated and accordingly it can be used in future feasibility studies concerning this product. Furthermore, to assess the overall acceptability of the fig molasses produced a sensory evaluation was conducted.

\section{MATERIAL AND METHOD}

\subsection{Fig Molasses Sample Preparation}

The materials used in this study are figs, which were morphologically classified into three categories namely green outer layer with white inside $(\mathrm{GW})$, green outer layer and red color inside (GR) and with red color outside and red color inside (RR).

Ripe fresh fig fruits were collected washed. Water (1:1 ratio) was added to the cleaned fig fruits and boiled until fig fruits became soft, able to be mashed. After that, the boiled ingredients were strained using a colander and cheesecloth such that the juice is separated from cooked figs. This fig molasses produced was placed in a pot and subjected to heat treatment until reaching sticky consistency close to that of honey (adjusted to $70^{\circ} \mathrm{Brix}$ ). On the other hand, the resulting strained cooked figs were recovered with water (one fourth the strained weight), cooked again, strained using a cheesecloth and then boiled for a second time to reach the desired brix.

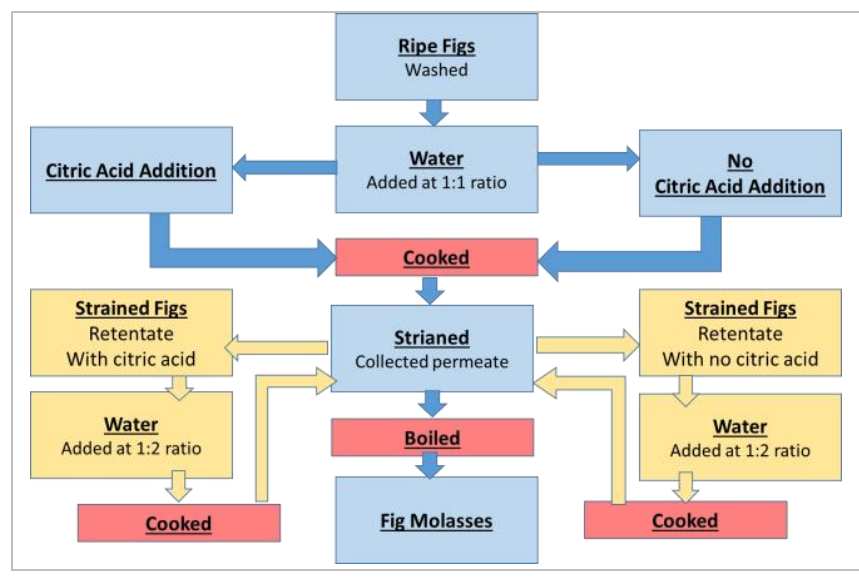

Fig.1: Fig molasses production flow

\subsection{Materials}

Brix Value Analysis: Brix Value was measured using Portable hand held RFM700 refractometer (Bellingham and Stanley LTD. United Kingdom).

Weight determination: Weight was measured using Portable electronic balance Model 727 was used to measure the weight with an accuracy of \pm 1 gr (Jata Hogar).

pH analysis: Microcomputer based $\mathrm{pH} /$ conductivity/TDS/salinity and temperature pocket meter Model $\mathrm{pH} / \mathrm{EC} 80$ was used to measure the $\mathrm{pH}$ (Jenco VisionP).

Water activity: It was determined using AQUALAB Pawkit Water Activity Meter. Samples were flattened to cover the bottom of the cup and then water activity was measured at room temperature (Nielsen, 2010).

Ash Determination: Ash was determined using the AOAC 942.05 method.

\subsection{Methods}

2.3.1 Effect of different cultivars on the fig molasses physicochemical properties and fig molasses production efficiency

Fig molasses from each cultivar, GW, GR and RR, was produced separately and tested for ash content, $\mathrm{pH}$ and water activity. Furthermore, the production efficiency of each cultivar was recorded by taking the initial weight of the fresh ripe figs and the weight of the fig molasses produced thus having the $\mathrm{Kg}$ fig molasses produced from $100 \mathrm{Kg}$ fresh ripe figs.

\subsubsection{Comparing Fig molasses produced from fresh ripe figs and those produced from the byproducts (strained figs) of the primary production}

Fig molasses produced from fresh ripe figs were produced and tested for ash, $\mathrm{pH}$ and water activity and most importantly fig molasses per $100 \mathrm{~kg}$ figs. These values were compared to the fig molasses produced from strained figs which is the byproduct of the primary production. No sensory analysis was conducted on fig molasses produced from the byproduct of the primary production due to time and quantity constrains.

\subsubsection{Effect of citric acid addition on the physicochemical properties and the production efficiency}

Fig molasses produced from fresh ripe figs were compare to those molasses produced without the addition of citric acid in terms of ash, $\mathrm{pH}$ and water activity and most importantly fig molasses per $100 \mathrm{~kg}$ figs. 


\subsubsection{Sensory attributes}

The sensory attributes include: sweetness with 0 having no sweetness and 5 having highest sweetness, sourness with 0 having no sourness and 5 having the highest sourness, color intensity with 0 being the brightest and 5 being the darkest one, aroma with 0 being the unpleasant and 5 being the most pleasant one, overall acceptability with 0 having lowest acceptability and 5 having the highest acceptability. In addition to that, the sensory score of each fig molasses was calculated by taking the mean of the different sensory attributes.

\subsection{Statistical analysis}

All tests and analysis were run in triplicates and averaged. General linear repeated measure model performed via SPSS (statistical Package for the Social Sciences, version 17.0) was used to study the fig molasses produced from different cultivars in terms of ash content, $\mathrm{pH}$, water activity, $\mathrm{kg}$ fig molasses per $100 \mathrm{~kg}$ figs and sensory score.

Furthermore, paired t-paired test was used to assess the difference between the fig molasses resulting from the fig cultivars with and without citric acid addition and Chi square was used to study if there is significant different in the score frequency distribution of each score per fig cultivar with and without citric acid. Thirty panelists did the sensory evaluation. Spearman correlation was used to assess the correlation between the different sensory attributes.

\section{RESULTS}

\subsection{Effect of different fig cultivars}

In this study no difference was detected in the ash content and $\mathrm{pH}$ of the fig molasses produced from the three local fig cultivars chosen for this study. There was, however, a significant difference in water activity between the molasses done from GR and that of the molasses done from the RR figs, while there was no significant difference in the water activity between the molasses done from the GW and that of molasses done from the GR and RR.

Table 1 Ash content, $\mathrm{pH}$ and water activity of the different fig cultivars

\begin{tabular}{llll}
\hline & GW & GR & RR \\
\cline { 2 - 4 } & Mean \pm SE & Mean \pm SE & Mean \pm SE \\
\hline $\begin{array}{l}\text { Ash Content } \\
\%\end{array}$ & $1.26^{\mathrm{a}} \pm 0.15$ & $1.06^{\mathrm{a}} \pm 0.15$ & $1.13^{\mathrm{a}} \pm 0.15$ \\
\hline $\mathrm{pH}$ & & & \\
\hline $\begin{array}{l}\text { Water } \\
\text { activity }\end{array}$ & $0.74^{\mathrm{a}} \pm 0.07$ & $4.76^{\mathrm{a}} \pm 0.07$ & $4.82^{\mathrm{a}} \pm 0.07$ \\
\hline
\end{tabular}

- Means with different letters among rows are significantly different

- GW is green outside layer and white content inside; GR is green outside layer and red content inside; RR is red outside layer and red content inside

As for the production-efficiency, it was accesses by measuring the $\mathrm{Kg}$ fig-molasses produced per $100 \mathrm{Kg}$ figs. There was no significant difference noticed between the amounts of molasses produced per $\mathrm{Kg}$ of the fig cultivar (Fig.2).

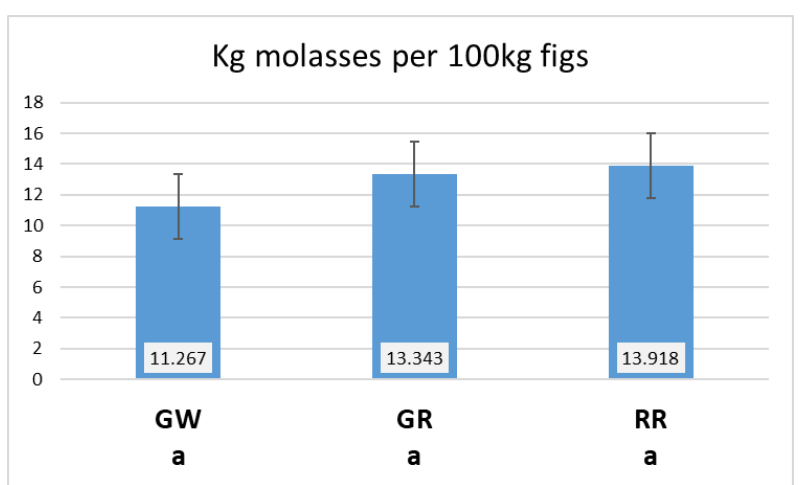

Fig.2: Effect of different fig cultivars on fig molasses production efficiency

(GW is green outside layer and white content inside; GR is green outside layer and red content inside; RR is red outside layer and red content inside)

\subsection{Fig molasses produced from fresh ripe figs and those produced from the byproducts (strained figs) of the primary production}

Following the procedure described in figure 1, we have fig molasses produced by the addition of 1 to 1 ratio of distilled water to fresh ripe figs (primary product) and those produced by the addition of 1 to 4 ratio of distilled water to strained figs (secondary product).

The ash content, $\mathrm{pH}$ and water activity of the of the primary and secondary product molasses did not differ significantly

Table 2 Ash content, $p H$ and water activity of primary product and secondary product

\begin{tabular}{llll}
\hline & Primary Product* & $\begin{array}{l}\text { Secondary } \\
\text { Product* }\end{array}$ \\
\cline { 2 - 5 } & Mean \pm SE & Mean \pm SE & \\
\hline Ash Content $\%$ & $1.214^{\mathrm{a}} \pm 0.108$ & $1.024^{\mathrm{a}} \pm 0.16$ & \\
\hline $\mathrm{pH}$ & $4,723^{\mathrm{a}} \pm 0.047$ & $4.876^{\mathrm{a}} \pm 0.07$ & \\
\hline Water activity & $0.826^{\mathrm{a}} \pm 0.016$ & $0.838^{\mathrm{a}} \pm 0.024$ & \\
\hline - Means with different letters & among rows are \\
significantly different & & &
\end{tabular}


- *: Primary product is fig molasses produced by the addition of 1 to 1 ratio of distilled water to fresh ripe figs; Secondary product is fig molasses produced by the addition of 1 to 4 ratio of distilled water to strained figs

In terms of the production efficiency indicator, the molasses produced from the fresh ripe figs (primary product) showed a significantly higher yield compared to molasses yield when strained figs were used (secondary product) (Fig. 3).

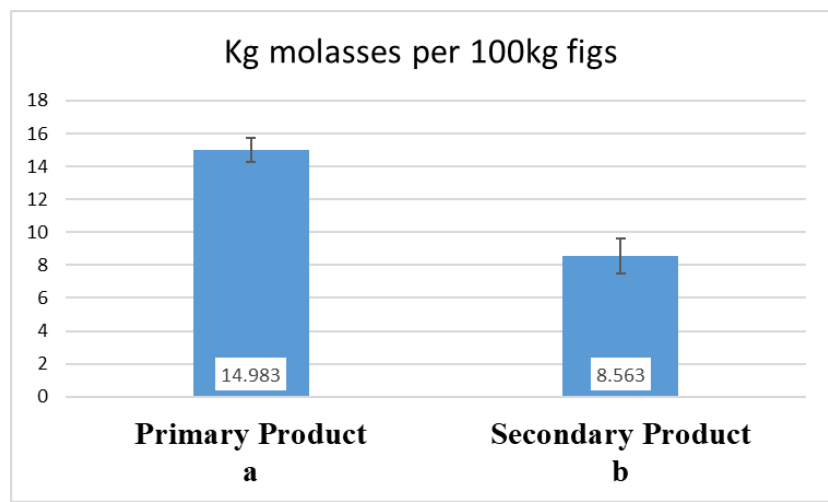

Fig.3: Comparison between primary and secondary product molasses in terms of production efficiency (Primary product is fig molasses produced by the addition of 1 to 1 ratio of distilled water to fresh ripe figs; Secondary product is fig molasses produced by the addition of 1 to 4 ratio of distilled water to strained figs)

\subsection{Effect of citric Acid addition}

Fig molasses, irrespective of the cultivar, done with the addition of citric acid to the figs before being cooked (Fig. 1) showed a significantly lower ash content and $\mathrm{pH}$ when compared to those done without the addition of citric acid. (Table 3). However, the water activity of both molasses showed no significant difference.

Table 3 Ash content, $\mathrm{pH}$ and water activity of fig molasses done without and with addition of citric acid

\begin{tabular}{|c|c|c|}
\hline & $\begin{array}{l}\text { Without } \\
\text { Acid }\end{array}$ & With Citric Acid \\
\hline & Mean \pm SE & Mean \pm SE \\
\hline Ash Content $\%$ & $1.309^{\mathrm{a}} \pm 0.108$ & $0.833^{\mathrm{b}} \pm 0.16$ \\
\hline $\mathrm{pH}$ & $5.078^{\mathrm{a}} \pm 0.047$ & $4.167^{\mathrm{b}} \pm 0.07$ \\
\hline Water activity & $0.815^{\mathrm{a}} \pm 0.016$ & $0.86^{\mathrm{a}} \pm 0.024$ \\
\hline
\end{tabular}

- Means with different letters among rows are significantly different

Concerning the chosen indicator of production efficiency citric acid addition resulted in a significantly higher fig molasses yield (Fig. 4).

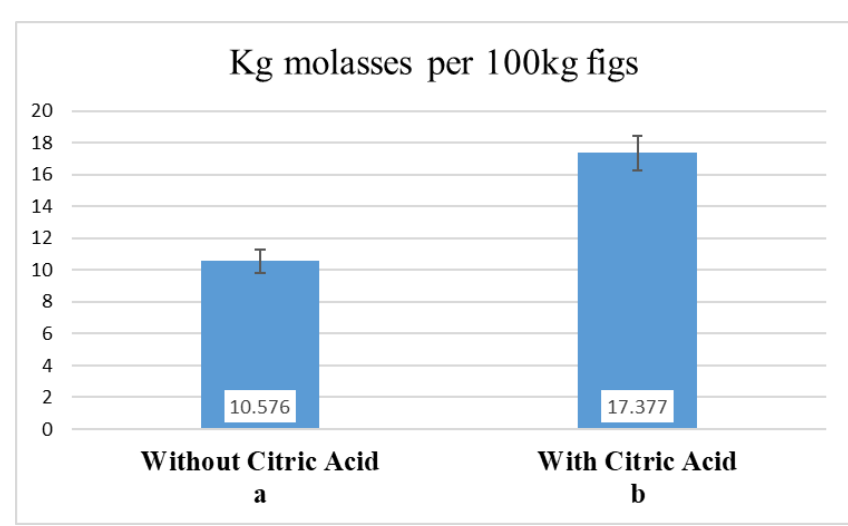

Fig.3: Effect of citric acid addition on fig molasses production efficiency

\subsection{Sensory attribute results of the different fig molasses produced}

The procedure followed in the production of fig molasses resulted in six fig molasses to be tested for their sensory attributes namely those molasses produced from the three local cultivars with and without citric acid addition (Fig. 1). Noting that molasses produced using the strained figs were not included in this study due to time and quantity constrains.

The sweetness, sourness and the aroma sensory attribute of fig molasses from the three chosen cultivars in Lebanon with and without the addition of citric acid showed no significant difference (Table 4). The mean values are between 3 and 4 .

Using chi square no significance was detected between the frequencies of score between the different sensory attributes recorded for the three chosen cultivars with and without citric acid. The highest frequency of panelists, for the above-mentioned sensory attributes, chose score 4 followed by score 3 then by the score 5 ending by the choice of the scores 2 and 1 being the lowest (Table 5).

Table 4 Sweetness, Sourness and aroma score means of fig molasses from different fig cultivars with and without citric acid

\begin{tabular}{llll}
\hline $\begin{array}{l}\text { Fig } \\
\text { molasses } \\
\text { source }\end{array}$ & Sweetness & Sourness & Aroma \\
\cline { 2 - 4 } & Mean \pm SD & Mean \pm SD & Mean \pm SD \\
\hline GW & $3.70^{\mathrm{a}} \pm 0.99$ & $3.73^{\mathrm{a}} \pm 0.98$ & $3.60^{\mathrm{a}} \pm 0.93$ \\
\hline GR & $3.73^{\mathrm{a}} \pm 0.94$ & $3.67^{\mathrm{a}} \pm 0.96$ & $3.63^{\mathrm{a}} \pm 0.89$ \\
\hline $\mathrm{RR}$ & $3.83^{\mathrm{a}} \pm 1.02$ & $3.77^{\mathrm{a}} \pm 1.01$ & $3.50^{\mathrm{a}} \pm 0.86$ \\
\hline GW + & & & \\
Citric & $3.57^{\mathrm{a}} \pm 1.07$ & $3.20^{\mathrm{a}} \pm 1.16$ & $3.40^{\mathrm{a}} \pm 1.07$ \\
\hline GR + Citric & $3.47^{\mathrm{a}} \pm 0.97$ & $3.20^{\mathrm{a}} \pm 1.10$ & $3.00^{\mathrm{a}} \pm 1.01$ \\
\hline RR + Citric & $3.73^{\mathrm{a}} \pm 0.87$ & $3.67^{\mathrm{a}} \pm 1.12$ & $3.00^{\mathrm{a}} \pm 0.80$ \\
\hline
\end{tabular}

- Means with different letters among rows are significantly different 
- GW is fig cultivar with green outside layer and white content inside; GR is with green outside layer and red content inside; RR is with red outside layer and red content inside

As for the color and overall acceptability scores of fig molasses produced from the different fig cultivars with and without citric acid, no significant difference could be detected (Table 6).

Table 5 Percentage of score choice by panelists per a sensory attribute

\begin{tabular}{llllll}
\hline Score & Sweetness & Sourness & Aroma & Color & Ov.Ac* \\
\hline 1 & 1.67 & 2.22 & 1.11 & 1.11 & 1.11 \\
\hline 2 & 9.44 & 17.22 & 11.67 & 8.33 & 15.00 \\
\hline 3 & 30.56 & 26.11 & 36.11 & 17.78 & 22.78 \\
\hline 4 & 36.67 & 33.89 & 35.56 & 50.00 & 42.78 \\
\hline 5 & 21.67 & 20.56 & 15.56 & 22.78 & 18.33 \\
\hline Sum & 100 & 100 & 100 & 100 & 100 \\
\hline
\end{tabular}

- *: Is overall acceptability

Concerning the panelist choice frequency no significant difference was detected between the different fig molasses and the highest percentage of panelist chose score 4 for color followed by score 5 then score 3 and consequently 2 and 1 being the lowest. As for the overall acceptability, like all other sensory attributes the choice of score 4 was the highest followed by score choice 3 then choice of score 5, 2 and 1 consequently (Table 5).

Table 6 Color and overall acceptability score means of fig molasses from different fig cultivars with and without citric acid (CA)

\begin{tabular}{lll}
\hline \multirow{2}{*}{$\begin{array}{l}\text { Fig } \\
\text { molasses } \\
\text { source }\end{array}$} & Color & Over all Acceptability \\
\cline { 2 - 3 } GW & Mean \pm SD & Mean \pm SD \\
\hline GR & $3.70^{\mathrm{a}} \pm 0.99$ & $3.73^{\mathrm{a}} \pm 0.98$ \\
\hline $\mathrm{RR}$ & $3.83^{\mathrm{a}} \pm 0.94$ & $3.67^{\mathrm{a}} \pm 0.96$ \\
\hline $\mathrm{GW}+\mathrm{CA}$ & $3.57^{\mathrm{a}} \pm 1.07$ & $3.77^{\mathrm{a}} \pm 1.01$ \\
\hline $\mathrm{GR}+\mathrm{CA}$ & $3.47^{\mathrm{a}} \pm 0.97$ & $3.20^{\mathrm{a}} \pm 1.16$ \\
\hline $\mathrm{RR}+\mathrm{CA}$ & $3.73^{\mathrm{a}} \pm 0.87$ & $3.67^{\mathrm{a}} \pm 1.12$ \\
\hline - Means with different & letters among rows are \\
significantly different & \\
- GW is fig cultivar with green outside layer and white \\
content inside; GR is with green outside layer and red \\
content inside; RR is with red outside layer and red \\
content inside
\end{tabular}

As for the sensory score, which is the mean of all the sensory attribute scores, there was no significant difference detected between the fig molasses produced from the different cultivars with and without citric acid (Fig. 4). Which complies with all the sensory analysis done before.

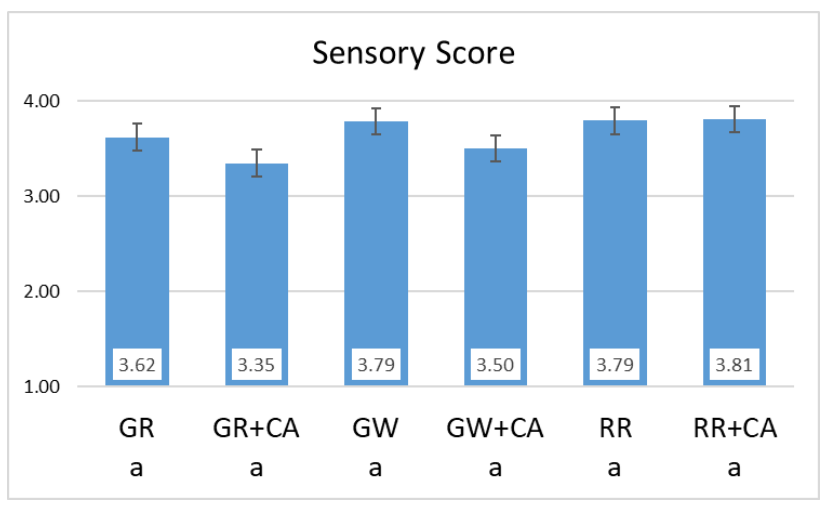

Figure 4 Sensory scores of fig molasses from different cultivars with and without citric acid (CA)

(GR is green outside layer and red content inside; GW is green outside layer and white content inside; RR is red outside layer and red content inside)

Applying spearman correlation it was found that all sensory attributes were positively and significantly correlated with each other. The overall acceptability was positively and highly correlated with the sweetness and sourness of the fig molasses. It was positively, significantly but medium correlated with the color and aroma sensory attributes.

Table 7 Spearman correlation of the different sensory attributes

\begin{tabular}{|c|c|c|c|c|c|}
\hline & $\begin{array}{l}\text { Sweetne } \\
\text { ss }\end{array}$ & $\begin{array}{l}\text { Sourne } \\
\text { ss }\end{array}$ & Color & $\begin{array}{l}\text { Arom } \\
\text { a }\end{array}$ & $\begin{array}{l}\text { Ov. } \\
\text { Ac }\end{array}$ \\
\hline $\begin{array}{l}\text { Sweetne } \\
\text { ss }\end{array}$ & 1 & $0.673^{* *}$ & $\begin{array}{l}0.286 \\
* *\end{array}$ & $\begin{array}{l}0.332 \\
* *\end{array}$ & $\begin{array}{l}0.758 \\
* *\end{array}$ \\
\hline Sourness & & 1 & $\begin{array}{l}0.390 \\
* *\end{array}$ & $\begin{array}{l}0.388 \\
* *\end{array}$ & $\begin{array}{l}0.720 \\
* *\end{array}$ \\
\hline Color & & & 1 & $\begin{array}{l}0.456 \\
* *\end{array}$ & $\begin{array}{l}0.494 \\
* *\end{array}$ \\
\hline Aroma & & & & 1 & $\begin{array}{l}0.560 \\
* *\end{array}$ \\
\hline $\mathrm{Ov} \cdot \mathrm{Ac}^{+}$ & & & & & 1 \\
\hline
\end{tabular}

- **: highly significant $p<0.01$

- +: Is overall acceptability

\section{DISCUSSION}

As for the physicochemical properties of fig molasses produced from the different fig cultivars there was no significant difference in terms of Ash content, $\mathrm{pH}$ and water activity. This is also true when comparing the $\mathrm{kg}$ 
molasses per kg figs. This suggests that we can collect ripe figs from different cultivars with no need of sorting especially that no significant difference was detected when comparing the score of sensory attributes of fig molasses produced from different cultivars.

Furthermore, the fig molasses from fresh ripe figs and those done from strained figs did not differ did not differ significantly in terms of Ash content, $\mathrm{pH}$ and water activity. Therefore it is advisable to do the secondary production since it will increase the production by one third. Just sensory analysis should be investigated later, although the physicochemical properties suggest no difference.

As for the results concerning the citric acid addition, it lead to lower ash content and, expectantly, lower $\mathrm{pH}$ although the water activity was not significantly different suggesting that it solubilized organic tissues (Cevrimli et al., 2009). Furthermore, it resulted in an increase in the yield of fig molasses by 1.64 times making the production more efficient. Furthermore, citric acid addition lowered the $\mathrm{pH}$ to less than 4.6 rendering it a high acid food and thus according to FDA standards safer.

Since fig molasses in traditionally done from extra ripe figs it targets the utilization of those figs which are difficult to utilize otherwise, thus reducing food wastage and showing the wisdom of the ways used in our heritage.

\section{CONCLUSION}

The results of this study suggested the addition of citric acid and the utilization of the byproduct of the primary fig molasses production namely the strained figs to increase the efficiency of production and the increase of fig molasses yield by more than one third. The no difference of the sensory scores among cultivars and with and without the citric acid addition strengthened the usage of citric acid, since it also makes the fig molasses produced in the high acid food category therefore considered safer and easier to conserve.

\section{REFERENCES}

[1] Aburjai, T., \& Natsheh, F. M. (2003). Plants used in cosmetics. Phytother Res, 17(9), 987-1000. doi:10.1002/ptr.1363

[2] Cevrimli, B. B., Kariptas, E., \& Ciftci, H. (2009). Effects of Fermentation Conditions on Citric Acid Production from Beet Molasses by Aspergillus niger. Asian Journal of Chemistry, 21, 3211-3218.

[3] Dimassi, O., Fawaz, R., \& Rached, M. (2019). EFFECT OF SOAKING TIME, INTERVAL, TEMPERATURE AND GROUND CAROB SIZE ON CAROB PERMEATE BRIX VALUE. 8, 472-481.

[4] Dimassi, O., Rached, M., Fawaz, R., \& Akiki, R. (2019). POLARIMETRY AND SPECTROPHOTOMETRY TO
DETECT ADULTERATION IN COMMERCIAL CAROB MOLASSES IN LEBANON.

[5] Flaishman, M., Rodov, V., \& Stover, E. (2008). The Fig: Botany, Horticulture, and Breeding. In (Vol. 34, pp. 113196).

[6] Gözlekçi, S., Erkan, M., Karasahin Yildirim, I., \& Şahin, G. (2008). Effect of 1-methylcyclopropene (1-MCP) on fig (Ficus carica cv. Bardakci) storage. Acta Horticulturae, 798, 325-330. doi:10.17660/ActaHortic.2008.798.47

[7] Jawandha, S. K., Singh, H., Kaur, K., \& Arora, A. (2016). Effect of pre-cooling on storage behaviour of peach fruit. 22, S311-S315.

[8] Kuchi, V., Gupta, R., \& Tamang, S. (2014). Standardization of recipe for preparation of guava jelly bar. Journal of Crop and Weed, 10, 77-81.

[9] Migdadi, H., Fayad, M., Ajloni, M., Syouf, M., Brake, M., K.Abulila, \& Z.Tahebsum. (2007). The Second Report on the State of the World's Plant Genetic Resources for Food and Agriculture.

[10] Nielsen, S. S. (2010). Food analysis ( 4th edition ed.). New York Dordrecht Heidelberg London: Springer.

[11] Polat, A. A., \& Caliskan, O. (2008). Fruit characteristics of table fig (Ficus carica) cultivars in subtropical climate conditions of the Mediterranean region. New Zealand Journal of Crop and Horticultural Science, 36, 107-115. doi:10.1080/01140670809510226

[12] Polat, A. A., \& Özkaya, M. (2005). Selection studies on fig in the Mediterranean Region of Turkey. Pak J Bot, 37, 567-574.

[13] Stover, E., Aradhya, M., Ferguson, L., \& Crisosto, C. (2007). The Fig: Overview of an Ancient Fruit. HortScience, 42. doi:10.21273/HORTSCI.42.5.1083

[14] Vallejo, F., Marín, J. G., \& Tomás-Barberán, F. A. (2012). Phenolic compound content of fresh and dried figs (Ficus carica L.). Food Chemistry, 130(3), 485-492. doi:https://doi.org/10.1016/j.foodchem.2011.07.032 